\title{
FROM NATIVE-SPEAKER LIKENESS TO SELF-REPRESENTATION IN LANGUAGE: VIEWS FROM THE ACQUISITION OF JAPANESE TRANSITIVE AND INTRANSITIVE VERBS
}

\author{
ITO Hideaki \\ University of Tsukuba, Japan \\ ito.hideaki.gb@u.tsukuba.ac.jp
}

\begin{abstract}
This study considers the degree to which a language user's own will is recognized in language education. It also looks at the use of Japanese transitive and intransitive verbs to reexamine the differentiation between language use that is native-like, and language use that is representative of the learner's self. The reexamination indicates that shifting previous approach to a more usage-centric acquisition process can create opportunities for language users to make expressive choices focused on what they wish to say. This shift may be accomplished by introducing backward design and critical pragmatics into teaching practices, thereby enabling the pursuit of self-representing language use, and prompting individuality in each learner without binding the learner solely to linguistic rules.
\end{abstract}

Keywords: transitive and intransitive verbs; discriminative knowledge; pragmatic choice; cultural literacy; diversity

\section{Povzetek}

Raziskava obravnava stopnjo prepoznavanja lastne volje uporabnika jezika pri jezikovnem izobraževanju. Obenem proučuje uporabo japonskih prehodnih in neprehodnih glagolov in ugotavlja njune razlike $v$ jezikovni rabi, predvsem razlike, ki nastanejo med ciljnim jezikom in jezikom učečega. Ugotovitve nakazujejo, da lahko sprememba k pristopu, ki je bolj osredotočen na pragmatično-usmerjeni učni proces, pripomore $k$ izboljšani izraznosti lastne volje učečega. To spremembo je moč doseči z uvedbo t.i. retroaktivne metode (angl. backward design) in kritične pragmatike v učni proces, s čimer učečemu omogočimo samoevalvacijo uporabe jezika in spodbujamo njegovo individualnost, ne da bi ga vezali zgolj na jezikovna pravila.

Ključne besede: prehodni in neprehodni glagoli, diskriminativno znanje; pragmatična izbira; kulturna opismenjenost; raznolikost 


\section{Introduction}

The CEFR (Common European Framework of Reference for Languages: Learning, teaching, assessment), published by the Council of Europe in 2001, understands language users to be social agents. This idea recognizes each person as a member of society regardless of his or her varying levels of linguistic proficiency. This may seem obvious, but let us consider the degree to which language education recognizes a language user's intention when learning a language.

For instance, one grammatical feature highlighted as difficult for learners of Japanese to acquire is verbal transitivity ${ }^{1}$ (also termed 'transitive-intransitive verbs' below) (Kobayashi, 1996). It is common when teaching the Japanese language to instruct learners to express their actions in Japanese as naturally occurring phenomena in order to avoid actively emphasizing those actions as their own doing. To give a specific example with (1) and (2) below, the sentence in (1) would often be considered 'correct' in the sense that it resembles what a native speaker would use.

(1) 不況で大変だったけど、やっと仕事が見つかったよ。

fukyō de taihen datta kedo, yatto shigoto ga mitsukatta yo

'It was tough with the recession, but work was found in the end.'

(2) 不況で大変だったけど、やっと仕事を見つけたよ。

fukyō de taihen datta kedo, yatto shigoto wo mitsuketa yo

'It was tough with the recession, but I found work in the end.'

In fact, both of these sentences are grammatically correct; it cannot be said that one is more correct than the other, or that only one of the expressions should be learned. There may be trends in the differentiated use of these expressions coming from the Japanese culture or the Japanese language itself, but as mentioned at the beginning of this paper, it is the language user who should decide how he or she wishes to speak. Meanwhile, an utterance will be based on the language user's own will only when that language user has judged what it is that he or she wishes to say. Societal diversity is ever more important at present, and in such times, it would seem problematic that, in Japanese language education, learners are being taught to use only particular turns of phrases based on existing usage trends. Learners of Japanese should therefore have the knowledge to be able to differentiate between and make proper

\footnotetext{
${ }^{1}$ Nakaishi (2005a) includes the verb combination hai-ru/ire-ru [enter/include] as comprising a 'paired intransitive verb' and a 'paired transitive verb.' The verbs in such pairs do not share a common root but are taught as transitive-intransitive verb pairs in elementary Japanese language textbooks. This paper addresses transitive-intransitive verb pairs in Japanese language education and therefore follows Nakaishi's (2005a) definition and terminology.
} 
use of 'native-speaker likeness' and 'self-representation' in their target language use. This paper reexamines what that knowledge comprises by looking at the example of transitive and intransitive verbs, usage of which can change according to differences in cognitive understanding. We will also consider why self-representation is vital in future education.

\section{Three Perspectives}

In examining what constitutes knowledge of the properly differentiated use of nativespeaker likeness and self-representation in this paper, we will refer to three perspectives: flexible language use; native speaker diversity, and pragmatic choice.

\subsection{Flexible language use}

One common topic in language education in Japan is 'native speaker worship' or 'native-speakerism', i.e., where native-level proficiency is considered the ultimate goal, be it in teaching Japanese, English, or any other language. Yoshitomi (2014) considers English language education in Japan in terms of the sociolinguistic categories of an 'inner circle', 'outer circle', and 'expanding circle'. The inner-circle includes nations and regions where English is societally standard as the main first language (L1), and the outer circle includes places such as India and Singapore where English has become distinct and societally standard as an official or semi-official language. The expanding circle features nations and regions such as Japan, China, Russia, and Spain where English is considered a foreign language. Yoshitomi asserts that language users within this category should not defer to norms defined by native speakers; linguistically varied English should instead be understood as equally valuable, and this unique variation should be used with confidence (Yoshitomi, 2014, p. 147). Yoshitomi thus both advocates for a departure from 'native-speakerism' and also asserts that, although native speakers are models for some aspects of language learning, it is unrealistic to treat such a model as a target in language education. Yoshitomi stresses the need to train users to convey what they wish to say even if they cannot think of the vocabulary or grammar that could most precisely express their intended meaning, be it by using the basic linguistic knowledge they do have or indeed through non-verbal means (Yoshitomi, 2014, pp. 148-149). In sum, regardless of deviation from native-speaker norms, there is still a need to foster flexible language use that incorporates verbal and non-verbal means available to the learner. 


\subsection{Native speaker diversity}

We have addressed the need to nurture flexible language use in language learners; let us now consider the case of Japanese L1 speakers. Makihara (2013) investigated selection tendencies in the use of transitive-intransitive verbs by undertaking a questionnaire survey of eight Japanese L1 university students. The results revealed that the choice between a transitive verb or an intransitive verb differed depending on the speaker's social relationship with his or her listener(s). Existing research has revealed diversity even in aspects of Japanese that had been taught to be used in a manner premised on tendencies of native speakers - saying, for instance, that a native speaker of Japanese would prefer a certain expression. Makihara (2016) also investigated selection tendencies in the use of transitive-intransitive verbs by conducting a questionnaire survey of 35 Japanese L1 university students who evaluated example utterances of transitive and intransitive verbs in simple and complex sentences. The results showed considerable variation in transitive-intransitive choices even amongst native speakers of Japanese. Nonetheless, Makihara (2016) notes that the existence of some variation does not necessarily mean that there is no basis for choices made by native speakers concerning their use of transitive-intransitive verbal forms, however, the following trends can still be observed:

1. If the speaker is more clearly responsible, a transitive verb is more likely to be used.

2. In complex sentences, the speaker is more likely to use a transitive verb sentence for an action that directly affects a target object, and for any resulting state.

This research shows that, in many cases, trends ultimately form the basis of what is considered 'correct' in teaching the Japanese language.

\subsection{Pragmatic choice}

Pragmatic choice concerns cases where learners are aware of the pragmatic norms and linguistically capable of producing native-like forms but make deliberate choices not to use them on particular occasions (Ishihara \& Cohen, 2014, p. 77). This means that, while a learner understands the pragmatic norms in the linguistic behavior of native speakers for particular expressions, he or she is not free from preconceptions about the world; rather, the learner is a social being with his or her cultural values, beliefs, and worldview, and accordingly, the question of how a person expresses him- or herself linguistically should be left to that person (Ishihara \& Cohen, 2014). This certainly aligns with the CEFR interpretation of language users as social agents. Indisputably, there is an intention behind each linguistic expression and a reason for its existence, which must be known in the context of additional language instruction. However, the idea of pragmatic choice, namely that the choice of linguistic expression should be left to the 
learner, has not yet garnered much discussion in teaching the Japanese language. Rather, this sort of thinking has been considered quite idealistic. However, our current era calls for diversity, including in language, and if we want language education to place importance on diversity, we should aim to teach in ways that actively allow for pragmatic choice.

\section{Changing ideas about acquiring discriminate knowledge}

In the field of Japanese language education, transitive and intransitive verb acquisition has been considered difficult because differences in language use can emerge from differences in cognitive understanding. This section will address how to change ideas about transitive and intransitive verb acquisition after outlining previous findings from transitive-intransitive verb acquisition research, centering on flexible language use, native speaker diversity, and pragmatic choice, as described in Section 2.

\subsection{Research in Japanese language education on the acquisition of transitive and intransitive verbs}

Kobayashi \& Naoi (1996), Morita (2004), Nakaishi (2005a, b), and Itō (2012) represent the core research on transitive and intransitive verb acquisition.

Kobayashi and Naoi (1996) showed how the misuse of several tasks, such as morphological judgments of lexical forms and discourse completion, made it difficult for learners in Mexican university to acquire intransitive verbs, particularly those that express resultative states such as kie-te-iru ('has disappeared'), through several tasks, including morphological interpretation of vocabulary and discourse completion. The study indicats stages of acquiring such verbs, from learning their morphology to using them pragmatically. Next, in Morita (2004), Australian learners were asked to interpret the morphological forms of transitive and intransitive verbs. No significant difference was found when their conversational ability and rate of correct responses to this task were compared. Interviews also revealed that learners encountered transitive verbs more frequently than intransitive verbs in explanations from their textbooks and instructors, and thus better understood transitive verbs. This suggests the possibility that the acquisition of transitive and intransitive verbs is burdened by the frequency of contact.

Nakaishi (2005a) investigated trends in learners' transitive and intransitive verb usage through video image tasks. The study found that intransitive verbs were more difficult to acquire than transitive verbs, and that individuals showed fixed acquisition patterns such as 'using a transitive verb for a particular conjugation (always use transitive verbs when there is a te-form such as kime-te kudasai).' 
Nakaishi (2005b) also conducted a study that made use of storytelling, noting a lack of research demonstrating that learners make suitably differentiated use of transitiveintransitive verb pairs in working contexts. The results showed that learners not necessarily differentiate between transitive and intransitive verbs consciously, and only use one of the forms (the one that they are accustomed to) in a variety of settings, that they are accustomed to.

Itō (2012) studied the use of transitive and intransitive verbs by Chinese learner data in the KY Corpus, a linguistic resource that includes transcriptions of oral proficiency interview tapes. The study asserts that it is necessary to implement a shift from morphological accuracy to pragmatic appropriateness in the focus of instruction, based on the learner's level of study.

In summary, the following key points are stated in the existing transitiveintransitive verb acquisition research detailed above:

1. Intransitive verb acquisition is difficult.

2. Contact frequency is relevant.

3. Lexical issues are relevant.

4. Usage and pragmatic acquisition are linked with a morphological acquisition.

Section 3.2 discusses transitive and intransitive verb acquisition in light of the findings from the above studies.

\subsection{Changing ideas about acquisition}

Stanovich, writing on vocabulary acquisition, states:

There is considerable agreement that much - probably most - vocabulary growth takes place through the inductive learning of the meanings of unknown words encountered in oral and written language. It appears that the bulk of vocabulary growth does not occur via direct instruction. (Stanovich, 1986, p. 379).

Additionally, Taylor states: "To know how to use a word, the speaker of a language would need to know specific facts about that word, facts which could only be acquired through exposure to how the word is used" (Taylor, 2012, p. 45). Nakaishi (2005b) also suggests that transitive and intransitive verb acquisition is possibly a vocabulary issue. Accordingly, we may suppose that, in transitive and intransitive verb acquisition, it is more efficient to have learners acquire morphological forms as part of pragmatic instruction rather than focus primarily on the morphological differences between individual words. This also ties into the usage-based categorization of transitiveintransitive verbs proposed by Itō (2017): 'transitive and intransitive verbs indicating situation construal' and 'transitive and intransitive verbs indicating situation report.' This perspective is also visible in the connection with contact frequency described by 
Morita (2004) and suggests the possibility that learners may in practice already be learning from pragmatic use.

The process of acquisition has previously been conceptualized in stages: a learner first acquires a form and then in the next stage acquires its usage. As in the morphocentric-type schema in Figure 1, the process starts from the morphological and syntactic opposition that is characteristic of Japanese transitive and intransitive verbs, e.g., aku/akeru ('open' (intr.)/'open' (tr.)). If we turn the morphocentric-type schema to the right, however, usage becomes the central focus around which forms are then involved. This enables us to change to the usage-centric type schema in Figure 1 without dismantling the process established in previous research. This creates an opportunity for language users to make expressive choices based on what they wish to say.

Morphocentric-type (conventional)

Modified from Nakaishi (2017)

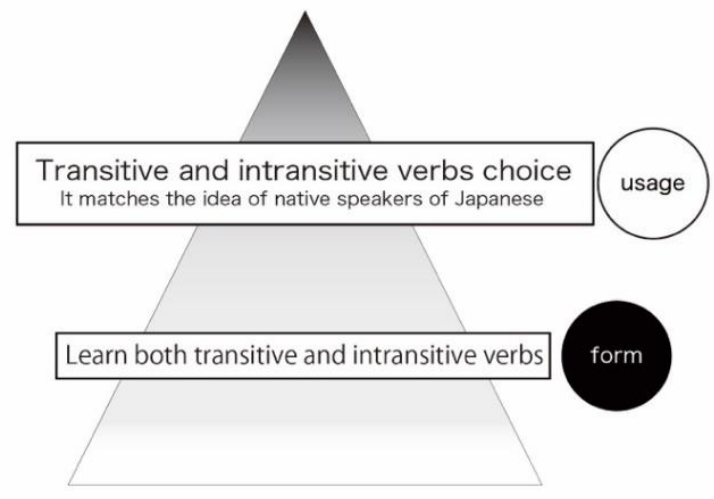

Usage-centric type

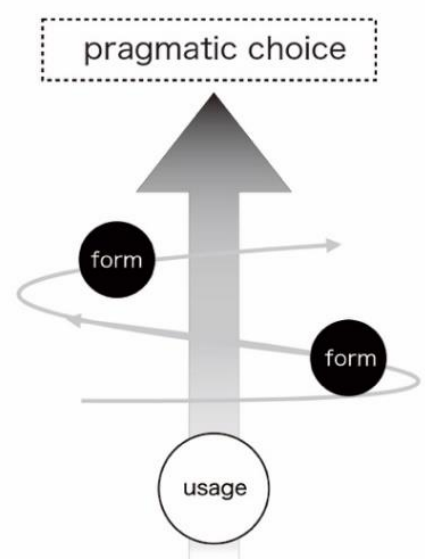

Figure 1: Changing the acquisition process of transitive and intransitive verbs

\section{Differentiating between self-representation and native-speaker likeness}

\subsection{Backward design in pursuit of self-representation}

Shirakawa (2005) provides the following example of improperly differentiated transitive-intransitive verb use.

(3) [きつくてなかなか開けられないビンのふたを開けて］*開けた！

[kitsu kute nakanaka akerare nai bin no futa wo akete] *ake-ta!

'The cap was stiff, so the bottle was hard to open [tr.], but I tried, and I did open [tr.] it.' (Shirakawa, 2005, p. 51) 
The learner perhaps thinks, "It was me who opened the bottle; the cap didn't come off by itself." When expressed with a transitive verb in Japanese like this, however, the utterance carries a boastful implication not intended by the speaker. According to Shirakawa, the learner is not aware of this unintended nuance, therefore rendering (3) erroneous (Shirakawa, 2005, p. 52). The study also posits the need for a more involved explanation when addressing improper use or non-use of expressions; as well as instruction in proper usage, learners also require an explanation of why other expressions are unsuitable (Shirakawa, 2005, p. 60). As discussed in the previous section, the common approach to transitive-intransitive verb acquisition has until now been gaining an understanding of the verbs' contrasting morphology, linking then to a pragmatic, usage-based understanding that includes tense and aspect. On the other hand, we can create the opportunity to confront ideas of 'native-speakerism' by factoring the following into our stages of instruction: first, further motivating the learner to speak by clarifying his or her actions and intentions/wishes, and then considering which expression is needed, and whether or not other expressions could be suitable, to accomplish linguistic behavior appropriate to the learner's intentions. By constructing classes in this manner, we can equip learners with the knowledge to properly differentiate between language use that resembles that of a native speaker and language use that is more representative of the learner's self, thus challenging 'native-speakers' approaches that ask learners to 'talk like a native speaker.'

Let us now discuss how we might construct classes in this manner. Wiggins and McTighe (2005) propose backward design as a method for planning learning that pursues specific understanding. The backward design follows the class-planning stages below (Figure 2), and the actual classes are conducted in practice from the third stage through to the first stage.

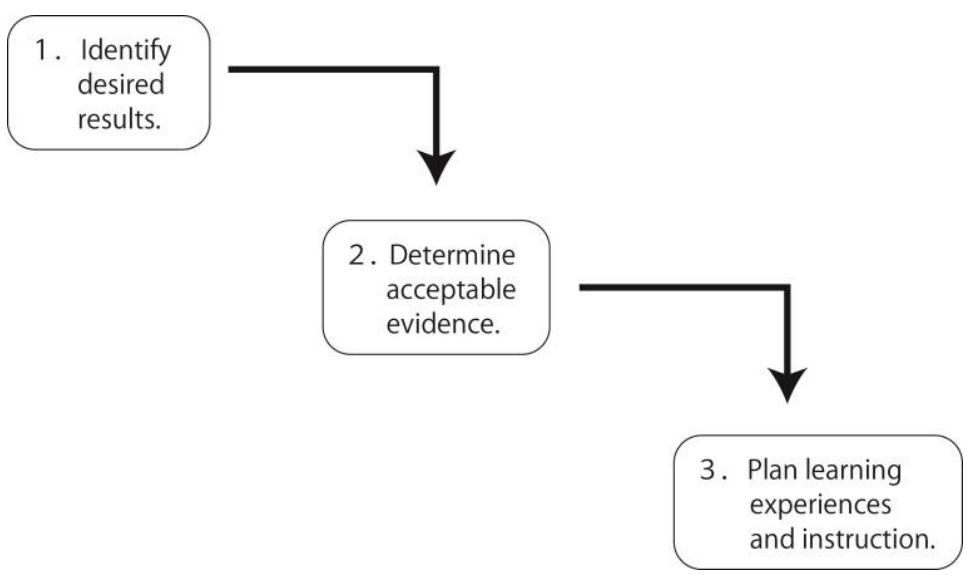

Figure 2: Stages of backward design (Wiggins \& McTighe, 2005, p. 18) 
First stage: Identify desired results.

First, identify what the student needs to learn, understand, and/or be capable of. The discussion above indicates that the biggest objective in learning Japanese transitive and intransitive verbs is for the learner to be able to convey what he or she wishes to say in light of pragmatic and cultural knowledge.

Second stage: Determine acceptable evidence.

Investigate how to determine whether the desired results established in the first stage have been achieved. If our desired result is for the learner to be able to convey what he or she wishes to say in light of pragmatic and cultural knowledge about Japanese language use, then it will be important to verify whether the learner has an understanding of pragmatic and cultural knowledge in the use of Japanese transitive and intransitive verbs and whether the learner is conveying what he or she wishes to say.

Third stage: Plan learning experiences and instruction.

Consider what manner of instruction would be most suitable for learning the material that needs to be verified in the second stage and plan individual classes. Here, we construct specific classes from what needs to be learned to gain an understanding of pragmatic and cultural knowledge in the use of Japanese transitive and intransitive verbs and from what needs to be learned for the learner to convey what he or she wishes to say.

One potential risk when putting an idea shift like this into practice is that merely emphasizing pragmatic instruction may lead to Japanese learners treating Japanese L1 speakers as an ideal end-goal model, only further solidifying native-speakers' ideas. To avoid native-speakerism here, there is a need for cultural literacy - that is, deciphering why particular linguistic behavior carries the meaning it does within the relevant culture. In the practice of teaching this cultural literacy, it is necessary to also include a critical pragmatics standpoint to help learners more readily judge whether or not to participate in those customs based on cultural information. This standpoint may be fostered by having learners study the pragmatic norms of the target language, discuss cultural perspectives with other learners and sometimes also native speakers, and thereby come to know why such norms exist in the target language (Ishihara, 2014). This may also lead to the recognition and correction of unequal vertical hierarchies that lead to native-speakerism in established stratified arrangements, such as the binary of 'native' versus 'non-native' speakers, and also consequentially lead to pragmatic choice 
as described in Section 2, which factors in properly differentiated use of both nativespeaker-like and self-representing language.

\subsection{What lies beyond the choice of self-likeness}

It is well known that the spread of COVID-19 has occasioned a sudden leap in the proliferation of online education. Perhaps this will lead to more active adoption of online classes in future education even after the pandemic has ended. Amidst this increased adoption of online approaches is a predicted increase in global co-learning courses, even in language education. In this case, note that the original aim of colearning (that is, coming into contact with diverse attitudes and values) will likely not be achieved merely under learners studying in the same setting.

Fadel et al. (2015, p. 67) collected curricula from 35 nations, regions, and organizations across the globe and sorted their educational goals into the following four dimensions:

1. Knowledge: What we know and understand

2. Skills: How we use what we know

3. Character: How we behave and engage in the world

4. Meta-learning: How we reflect and adapt

In the interests of space, the authors' original work should be referred to for elaboration on each of these dimensions; the important point here is that future education includes character, a dimension separate from knowledge and skills. For Fadel et al. (2015), character includes mindfulness, curiosity, courage, resilience, ethics, and leadership. These elements relate to the individual identities of learners and, thus, to the idea of self-representation discussed in this paper.

As global co-learning courses proliferate in the future, let us cultivate character in each learner, not by binding solely to linguistic rules but by adopting the aforementioned critical pragmatics standpoint in our practice and aiming for selfrepresentative language use.

\section{Summary and future topics}

This paper began with an inquiry into the degree to which a language user's own will is recognized in language education. Learners of the Japanese language should know to be able to differentiate between and make proper use of native-speaker likeness and selfrepresentation in the language; this paper reexamines what that knowledge is by looking at the example of transitive and intransitive verbs, usage of which can differ depending on differences in cognitive understanding. The process for learner acquisition of Japanese transitive and intransitive verbs has conventionally started with learning forms and then 
moving to usage, drawing on the morphosyntactic opposition characteristic of such verbs. This paper has noted, however, that by shifting our approach to a more usage-centric acquisition process, we can create the opportunity for language users to make expressive choices based on what they wish to say. We next looked to designing classes to foster knowledge for proper differentiation between native-speaker likeness and selfrepresentation with transitive and intransitive verbs by identifying through backward design the foundations of what learners need to know and learn; we further noted the importance of including critical pragmatics in our practice rather than merely emphasizing pragmatic instruction. Finally, the paper asserted that adopting this critical pragmatics standpoint in teaching practices and aiming for self-representing language use will link to cultivating character in each learner without binding the learner solely to linguistic rules. We have previously seen an idealistic discussion about studying and using the Japanese language concerning the views and ideas of learners. However, the proliferation of online education, which is only being accelerated by COVID-19, indicates that pro-diversity education must not be brushed aside as idealistic, and indeed we should aim to make it an actual reality. Accordingly, it is likely to become increasingly important to break free from adhering to native speaker norms; to side with learners, teaching them how to properly differentiate language use and enabling them to express themselves in self-representing ways; and to cultivate the character of each learner.

\section{Acknowledgments}

This work was supported by JSPS KAKENHI under Grant JP18K12419; and JSPS KAKENHI under Grant JP18H00680.

\section{References}

Ishihara, N. (2014). Chapter 6: Theories of language acquisition and the teaching of pragmatics. In N. Ishihara \& A. D. Cohen (Eds.), Teaching and learning pragmatics: where language and culture meet (pp. 99-122). London: Routledge.

Ishihara, N., \& Cohen, A. D. (2014). Chapter 5: Learners' pragmatics: potential causes of divergence. In N. Ishihara \& A. D. Cohen (Eds.), Teaching and learning pragmatics: where language and culture meet (pp. 75-96). London: Routledge.

Itō, H. (2012). How do learners use transitive-intransitive verb pairs? A study of intermediate to higher-advanced Chinese learners of the Japanese language. Journal of International and Advanced Japanese Studies, 4, 43-52. https://doi.org/10.15068/00129435

Itō, H. (2017). Usage-based perspectives on transitive-intransitive verb pairs: using the balanced corpus of contemporary written Japanese. Researching Japanese and the Teaching of Japanese, 9, 103-118.

Kobayashi, N. (1996). Expression of results and states with relative intransitive verbs: acquisition by learners of the Japanese language. Literature and Linguistics, 41-56. 
Kobayashi, N., \& Naoi, E. (1996). Are [Japanese] relative transitive-intransitive verbs learnable? A study of Spanish speakers. Japanese Language Teaching Journal, 11, 83-98.

Shirakawa, H. (2005). Teaching Japanese through a grammar independent from Japanese language research. In H. Noda (Ed.), A grammar for teaching communicative Japanese (pp. 43-62). Tokyo: Kurosio Publishers.

Nakaishi, Y. (2005a). A second language study on transitive-intransitive verb pairs: an analysis of the uses of 'tsuku/tsukeru,' 'kimaru/kimeru' and 'kawaru/kaeru'. Japanese Language Education, 124, 23-32.

Nakaishi, Y. (2005b). Do learners make properly-differentiated use of transitive and intransitive verbs? A transitive-intransitive verb pair acquisition study using utterance surveys. In M. Minami (Ed.), New directions in applied linguistics of Japanese (151-161). Tokyo: Kurosio Publishers.

Nakaishi, Y. (2017). Routes to acquiring Japanese transitive-intransitive verbs and their appropriate teaching methods [distributed material]. A Public Symposium on Japanese Transitive-Intransitive Verbs.

Makihara, T. (2013). Controlling gestures and expressions of consideration. Japanese Communication Theory, 3, 63-72.

Makihara, T. (2016). State construal and expression: transitive and intransitive verb selection. In M. Ōno \& Q. Li (Eds.), Subjectivity in language: the interface between cognition and politeness (pp. 151-171). Tokyo: Kurosio Publishers.

Fadel, C., Bialik, M., \& Trilling, B. (2015). Four-dimensional education: the competencies learners need to succeed. La Vergne, TN: Lightning Source, Inc.

Morita, M. (2004). The acquisition of Japanese intransitive and transitive paired verb by English speaking learners: case study at the Australian National University. JapaneseLanguage Education Around the Globe, 14, 167-192.

Stanovich, K. E. (1986). Matthew effects in reading: some consequences of individual differences in the acquisition of literacy. Reading Research Quarterly, 21(4), 360-407.

Taylor, J. R. (2012). The mental corpus: how language is represented in the mind. Oxford: Oxford University Press.

Wiggins, G., \& McTighe, J. (2005) Understanding by design (expanded 2nd ed.). Alexandria, VA: Association for Supervision and Curriculum Development.

Yoshitomi, A. (2014). English as a lingua franca. In CLT Project, Sophia University (Ed.), Proficiency of English as an international language, considering communicative English teaching: theories and practices for language education in Japan (pp. 146-149). Tokyo: ALC Press Inc. 